\title{
Komposisi Jenis Herba Pasca Kebakaran di Kalampangan-Kalimantan Tengah sebagai Awal Proses Suksesi Sekunder
}

\section{Herbaceous Plants Composition in Kalampangan, Central Borneo, Early of Secondary Succession Process Pasca Fost Fire}

\section{Asep Sadili}

Bidang Botani, Puslit Biologi-LIPI

Jl. Raya Jakarta-Bogor, Km 46, Cibinong 16911

E-mail: asep.sadili@gmail.com

\begin{abstract}
In the early stage of secondary succession process in 1 year old fost fire Kalampangan feat swamp area it was conducted a study on herbaceous plant species composition. The research found 6 fern species and 1 grass species out of 23 species representing 20 families. The coverage area of herbaceous vegetation was $13.12 \%$ or $1.312 \mathrm{~m}^{2}$ per hectare, which indicated relatively low percentage. In terms of relative dominance and frequency, herbaceous plant species in the area study was highly dominated by a terrestrial fern Stenochlaena palustris. Some tree species known as secondary and primary forest constituents such as Macaranga caladifolia (Euphorbiaceae), Dyera lowii (Apocynaceae), Combretocarpus rotundatus (Combretaceae), Cratoxylon arboresncens (Clusiaceae), Garcinia sp. (Clusiaceae) and Ploinarium alterifolium (Theacee) were found at their early growth stage on the forest floor but still in lower abundance compared to other recorded species from the study.
\end{abstract}

Key words: Species composition, secondary succssetion, fost fire, Kalampangan feat swamp

\begin{abstract}
Abstrak
Tahap awal proses suksesi sekunder berumur 1 tahun setelah terjadinya kebakaran hutan telah dilakukan penelitian mengenai komposisi jenis herba di arel Hutan Gambut Kalampangan. Dari penelitian ini ditemukan 6 jenis paku dan 1 jenis rumput dari total 23 jenis yang mewakili 20 famili. Penutupan areal dari vegetasi herba sebesar $13.12 \%$ atau $1.312 \mathrm{~m}^{2}$ per ha, dan hal ini menunjukkan masih rendah persentase penutupannya. Berdasarkan dominasi dan frekuensi relatifnya, jenis herba di lokasi penelitian didominasi oleh jenis paku terestrial Stenochlaena palustris. Beberapa jenis pohon yang diketahui merupakan jenis penyusun hutan sekunder dan primer seperti Macaranga caladifolia (Euphorbiaceae), Dyera lowii (Apocynaceae), Combretocarpus rotundatus (Combretaceae), Cratoxylon arboresncens (Clusiaceae), Garcinia sp. (Clusiaceae) dan Ploinarium alterifolium (Theacee). Jenis-jenis tersebut merupakan sebagai fase awal di lantai hutan, tetapi masih dalam kemelimpahan yang rendah dibandingkan dengan jenis lainnya yang tercatat dalam lokasi penelitian.
\end{abstract}

Kata kunci: Komposisi jenis, suksesi sekunder, kebakaran, gambut Kalampangan

Diterima: 01 Mei 2009, disetujui: 03 Maret 2010

\section{Pendahuluan}

Kekayaan hutan tropik Indonesia berupa bentangan alam dari kawasan hutan pegunungan sampai hutan dataran rendah merupakan kekayaan alam yang perlu dilestarikan, salah satunya kawasan hutan dataran rendah rawa gambut (Peat Swamp Forest). Kawasan rawa gambut mempunyai keunikan yang khas yaitu berair coklat dan mempunyai tingkat serasah yang sangat tebal serta berperan sebagai gudang karbon dalam unsur rumah kaca. Luas kawasan hutan gambut di Indonesia diperkirakan sekitar 27 juta ha. atau $60 \%$ dari seluruh luas kawasan hutan gambut tropika, tersebar dari Pulau Sumatera, Kalimantan, dan Papua (Simbolon, 2004). 
Terdapat dua Kawasan hutan gambut di Kalampangan-Kalimantan Tengah, yakni kawasan hutan gambut alami tidak terbakar dan hutan pasca kebakaran. Kawasan hutan gambut alami merupakan kawasan hutan primer yang masih utuh sebagai bagian dari kawasan hutan konservasi Sebangau, sedangkan kawasan hutan pasca kebakaran adalah bagian sisa kawasan hutan produksi tebang pilih pada tahun 1980an yang kemudian dijadikan proyek pertanian lahan gambut sejuta hektar yang telah gagal.

Akibat dari kemarau panjang dan iklim ENSO (El Nino Soutern Oscillation) keadaan kawasan lahan gambut Kalampangan sejuta hektar telah mengalami dua kali kebakaran yang sangat besar. Menurut informasi penduduk setempat kebakaran pertama terjadi pada bulan Desember 1997 dan September 2002 (komunikasi pribadi). Kebakaran September 2002 di Kalampangan ini keadaanya lebih parah dibandingkan dengan kebakaran 2007 . Jenisjenis tumbuhan yang ada seluruhnya hangus terbakar termasuk jasad renik didalamnya, hal ini terlihat dari adanya perubahan kondisisi lingkungan yang drastis terutama warna tanah yang hitam gelap, sehingga diprediksi tidak akan ada lapisan organik untuk tempat hidup mikroorganisme atau mikroba sebagai agen dekomposer dalam waktu relatif cepat (Viro (1974); Cass et al., (1984); Pietikainen dan Fritz (1996); Bazzaz (2000); Flaningan et al., (2000) dalam Rahajoe et al., (2004).

Dengan terdapatnya kawasan hutan gambut Kalampangan pasca kebakaran kedua yang telah berumur \pm 1 tahun, merupakan areal laboratorium alam yang sangat berharga terutama dalam mempelajari proses perkembangan suksesi sekunder. Proses ini memerlukan waktu yang cukup lama untuk menjadi kawasan hutan gambut alami yang utuh dan klimak. Oleh karena itu, sangat perlu dimonitor keberadaanya sehingga akan diketahui tahapan-tahapan yang terjadi pada setiap periode itu.

Dalam proses suksesi sekunder di atas, jenis-jenis paku, herba, dan semai telah tumbuh dan berkembang menutupi lantai kawasan hutan yang menandakan telah dimulainya proses suksesi pendahuluan untuk menutupi lantai hutan. Kemudian dalam rangka melengkapi informasi suksesi ini, dilakukan penelitian analisis vegetasinya secara kuantitatif yang diharapkan dapat berguna untuk ilmu pengetahuan dan dasar-dasar pengambilan kebijakan pengelolaan hutan gambut dalam pemulihan kawasan akibat adanya kebakaran khususnya di Kalampangan ini.

\section{Metode Penelitian}

Penelitian ini dilakukan didekat stasion penelitian Universitas Palangka Raya berjarak $\pm 1 \mathrm{~km}$ dari penelitian petak permanent Simbolon pasca kebakaran atau $\pm 1.5 \mathrm{~km}$ dari hutan gambut alami tidak terbakar. Posisi geografisnya terletak pada titik koordinat $\pm 02^{\circ} 18^{\prime} 25^{\prime}$ ' lintang selatan dan $114^{\circ} 02$ ' 32 ' bujur timur dengan ketinggian tempat $\pm 15 \mathrm{~m}$ dari permukaan laut. Secara administratif pemerintahan lokasi tersebut termasuk ke dalam Desa Truna Jaya, Kecamatan Kalampangan, Kabupaten Palangka Raya, Propinsi Kalimantan Tengah (Gambar 1).

Keadaan umum lokasi penelitian secara keseluruhan dan ciri khas kawasan hutan rawa gambut di Kalampangan pasca kebakaran tersebut sudah tidak terlihat lagi layaknya hutan gambut alami. Serasahnya hampir seluruhnya habis terbakar menjadi abu sangat hitam yang disinari matahari langsung setiap harinya dengan $\mathrm{pH}$ tanahnya sangat asam 3,3-3,6. Jenis-jenis kayu berukuran diameter kecil yang tumbuh setelah terjadi kebakaran pertama Desember 1997 sebagian besar telah menjadi arang dan seluruhnya tumbang ke lantai, tetapi kayu berukuran diameter cukup besar masih tegak merangrang, tetapi menandakan akan mati juga. Lantai hutan lebih banyak yang kering dan ada pula yang masih basah bahkan tergenang air. Penyebab keringnya lantai hutan gambut ini diprediksi akibat dibuatnya kanal yang besar sehingga air sebagian besar mengalir ke kanal tersebut. Jenis-jenis jamur, lumut atau jenis lainnya yang termasuk tumbuhan rendah terutama yang hidup pada kayu-kayu mati belum banyak yang tumbuh akibat kayu-kayunya sebagian besar telah menjadi arang.

Cara kerja yang dilakukan pada penelitian ini yaitu dengan metode baku untuk penelitian tumbuhan tingkat semai atau herba dengan membuat petak cuplikan memanjang berukuran $2 \times 200 \mathrm{~m}\left(400 \mathrm{~m}^{2}\right)$. Petak tersebut dibagi menjadi 
petak-petak kecil berukuran $1 \times 1 \mathrm{~m} \quad\left(1 \mathrm{~m}^{2}\right)$. Kemudian jenis-jenis yang ada dalam petak kecil tersebut diukur persentasi tutupannya. Jenis-jenis yang tercatat sebagian daunnya dikumpulkan dibuat herbarium untuk diidentifikasi nama jenis ilmiahnya sebagai spesimen bukti (voucher). Data-data dari penelitian ini kemudian dianalisis menggunakan pormula Greig-Smith (1964). Karena yang diteliti berupa herba dengan komposisi jenis yang sifat hidupnya menjalar sehingga yang dicacah persentase tutupannya dari setiap jenis yang ada dalam petak, oleh karena itu nilai penting yang dicapai pada penelitian ini terdiri dari dua unsur yaitu dominasi relatif (DR) dan frekuensi relatif (FR).

\section{Hasil dan Pembahasan}

Keanekaragaman dan komposisi jenis tumbuhan adalah salah satu penyusun keberadaan banyaknya jenis tumbuhan dalam suatu komunitas kawasan hutan (MullerDumbois Ellenberg, 1974). Kaitan dengan pernyataan tersebut adalah keadaan komposisi jenis-jenis tumbuhan herba, paku-pakuan, semai, dan rumput sebagai penutup lantai hutan pada areal bekas terbakar yang merupakan awal dimulainya proses suksesi sekunder di Kalampangan.

Salah satu faktor utama yang mempengaruhi proses suksesi alami akibat adanya kerusakan lingkungan khusunya di Kalampangan pasca kebakaran ini adalah keadaan jenis tanah. Jenis tanah adalah habitat utama jenis-jenis tumbuhan untuk tumbuh dan berkembang menutupi lantai hutan dalam pemulihan kawasan hutan. Hal ini sangat relevan pada kondisi kawasan tersebut, karena keadaannya berbeda dari keadaan sebelumnya, sehingga hanya jenis-jenis tertentu saja yang dapat tumbuh dan berkembang secara normal walaupun kondisi tanahnya sangat ekstrem.

\section{Komposisi Jenis}

Hasil penelitian komposisi jenis-jenis tumbuhan herba, paku-pakuan dan rumput untuk menutupi lantai hutan pasca kebakaran (berumur \pm 8 bulan) untuk pemulihan kawasan hutan di Kalampangan ini menunjukan masih rendah dan tercatat baru seluas $13.12 \%$ atau seluas $1.312 \mathrm{~m}^{2}$ yang telah tertutup untuk setiap hektarnya. Dikatakan rendah karena dari beberapa informasi untuk pemulihan kawasan hutan umumnya kurang dari satu tahun jenis-jenis herba dan semak telah hampir menutupi kawasan yang mengalami perubahan, dan kemudian disusul jenis-jenis pionir tumbuhan hutan sekunder. Akan tetapi kerusakan kawasan disebabkan oleh kebakaran di Kalampangan ini menujukan sangat lambat dalam proses pemulihannya. Hal ini diperkirakan akibat matinya jasad renik sebagian besar sebagai agen dekomposer pada saat terjadi kebakaran, karena kebakaran yang kedua ini lebih parah dibandingkan dengan kebakaran pertama.

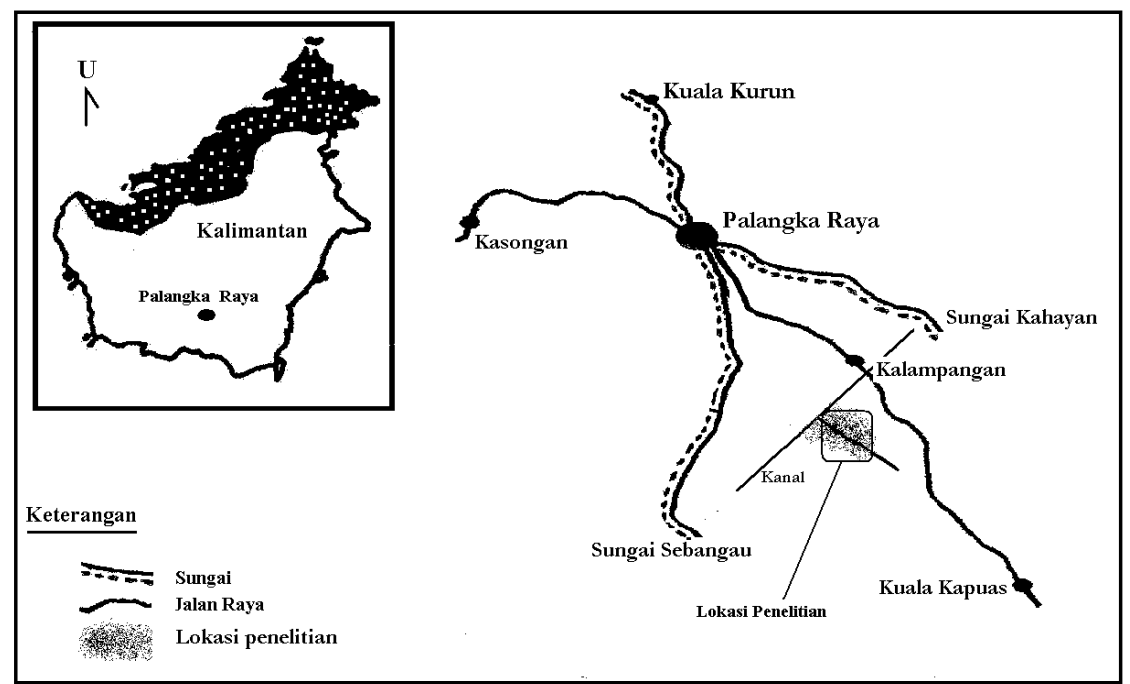

Gambar 1. Lokasi penelitian jenis herba pada hutan gambut pasca kebakaran di Kalampangan-Kalimantan Tengah. 
Berdasarkan hasil identifikasi spesimen bukti, komposisi jenis, marga, dan suku pada lokasi penelitian menunjukkan tidak bervariasi, dan hasil yang dicapai dari penelitian ini yakni tercatat sebanyak 23 jenis dari 20 suku, diantaranya sebanyak 6 jenis termasuk pakupakuan dan 1 jenis tergolong rumput (Tabel 1). Pernyatan ini juga didukung oleh Gambar 2 yang menujukan pada anak petak 169 penambahan jenisnya sudah mulai konstan atau stabil, walaupun ada penambahan tetapi tidak signifikan. Persentase tutupannya diperkirakan akan terus berkembang sampai pada batas maksimal kemudian akan disusul oleh jenis-jenis pioner berikutnya seperti jenis-jenis perdu atau jenis pohon hutan sekunder muda.

Variasi jenis yang telah terdata di atas diprediksi tidak akan tinggi seperti hutan-hutan dataran rendah lainnya, karena dari hasil penelitiannya Simbolon (2004) sebagai sumber utama persebaran jenisnya menujukan bahwa pada hutan gambut alami di Kalampangan ini untuk tingkat pohon, komposisi jenisnya lebih rendah dibandingkan dengan keanekaragaman jenis tipe ekosistem lain di hutan dataran rendah hujan tropik, atau sebanding dengan hutan pegunungan. Namun pada lokasi hutan gambut alami Kalampangan berbeda dengan komposisi hutan lainnya yaitu mempunyai populasi pohon yang cukup tinggi.

Jenis tumbuhan menjalar seperti Erycibe sp. (Convolvulaceae), Nephentes sp. (Nephentaceae), Morinda rigida dan Psychotria sp (Rubiaceae) telah menutupi lantai hutan pada tempat-tempat yang sedikit kering tetapi dari hasil analisisnya masih dibawah jenis-jenis paku-pakuan. Jenis Nephentes sp. yang tercatat pada petak yang diukur tumbuh dari trubus berukuran tinggi $\pm 5 \mathrm{~cm}$ yang diduga pada saat terjadi kebakaran hanya sebagian batang yang terbakar. Akar dan batang yang berada dalam bawah tanah dimungkinkan tidak mati, sehingga masih bisa untuk tumbuh. Jenis Erycibe sp, Morinda rigida dan Psychotria sp. sulit diprediksi karena tumbuh menjalar dengan kondisi perawakan normal dewasa terdapat hampir pada kondisi lantai tanah agak kering.

Selain jenis yang menjalar pada Tabel 1, seperti Macaranga caladifolia, Picus cf deltoidea, Ploinarium alterinifolium, Melastoma malabatricum, dan Combretocarpus rotundatus. dimungkinkan tumbuh berasal dari biji, karena pertumbuhnnya masih relatif muda, walaupun jenis tersebut tidak dari bank biji yang tersimpan dalam tanah kemungkinan berasal dari hutan alami yang tidak terbakar sekitar sebangau.

Jenis-jenis pohon pionir akibat adanya gangguan habitat utama untuk mengganti penutupi lantai hutan menuju hutan sekunder dari suku-suku Euphorbiaceae atau suku yang lainnya belum banyak yang muncul dan hanya Macaranga caladifolia (Euphorbiaceae), Cratoxylon arboresncens (Clusiaceae), dan Ploinarium alterifolium (Theaceae). Jenis $C$. arborescens adalah salah satu dari beberapa jenis sebagai penyusun utama kawasan hutan gambut sekunder yang paling dominan dan merajai sebagian besar kawasan yang telah terjadi rusaknya hutan gambut di Kalimantan.

Proses munculnya tumbuhan pada suksesi untuk pemulihan menuju hutan alami kembali akibat dari kerusakan lingkungan ini disebarkan oleh persebaran biji yang cepat oleh angin atau burung dari hutan alami, atau terdapat biji dorman sangat lama dalam tanah yang dalam, sehingga biji tidak ikut terbakar. Kemudian pada waktu tertentu dengan adanya intensitas cahaya matahari menembus lantai yang cukup tinggi maka biji dapat berkecambah walaupun keadaan tanah sangat miskin unsur haranya, hal tersebut terlihat adanya semai Combretocarpus rotundatus Danser., Ctenolophon parvifolius Oliver., Garcinia sp. dan Adenanthera paponina Linn.

Dari suku rumput-rumputan yang tercatat dalam petak yaitu jenis Imperata cylindrica, Jenis ini persentasi tutupannya masih rendah, tetapi tampaknya akan menguasai pada areal yang permukaan tanah relatif tinggi atau pada lantai hutan yang kering, karena keadaan petak cuplikan secara umum tanahnya basah kadang terdapat genangan air.

Jenis-jenis paku tanah yang tercatat hasil penelitian ini pada habitat dan kondisi lingkungan yang ekstrem tidak berpengaruh besar terhadap sebaran dan berkecambahnya spora untuk tumbuh dan berkembang pada lantai hutan akibat dari kebakaran tersebut jika dibandingkan dengan jenis tumbuhan lainnya yang telah terdata. Jenis-jenis paku tanah dalam suksesi sekunder untuk rehabilitasi kawasan gambut ini mempunyai tingkat variasi jenisnya 
masih sangat rendah, dibandingkan dengan jumlah jenis yang telah terdata di pulau Kalimantan, yaitu sebanyak 224 suku tetapi jenis-jenis yang endemik dilaporkan sedikit (Holttum, 1965; Sastrapradja, 1979; Anderson 1963 dalam Mackinon at al, 1994).

Keadaan jenis-jenis paku tanah $(S$. palustris, $B$. orientale dan $N$. Hirsutula) yang mendominasi tersebut dimungkinkan alat generatif menggunakan spora untuk bekembang biak sangat sesuai dalam menutupi lantai hutan akibat adanya gangguan sebelum jenis lainnya menyusul tumbuh. Selain adaptasi cukup tinggi terhadap dan ektrimnya habitat (kandungan kimia tanah, $\mathrm{pH}$ tanah dll.), jenis-jenis paku tanah tersebut mempunyai ukuran spora sangat kecil dengan jumlah yang cukup banyak dan ringan sehingga persebarannya akan lebih cepat apabila dibantu oleh angin dan mencapai ratusan meter dari induknya lalu berkecambah dan tumbuh normal.

Jenis paku S. palustris (Burm.) Bedd. di Kalampangan tumbuh subur berbatang menjalar populasinya melimpah dan mendominasi terutama pada kawasan lantai hutan yang tanahnya agak berair atau tanah basah dengan warna daun hijau kadang kekuningan. Pada tanah agak kering terutama pinggiran kanal pertumbuhannnya kurang normal dibandingkan dengan habitat yang sedikit berair, daunnya terlihat berwarna hijau pucat.

Jenis-jenis paku tanah Kalampangan terdapat juga di kawasan lain dengan habitat yang berbeda-beda. Menurut Haines dalam Holttum (1965) hasil penelitiannya di Malaysia, untuk suku Glichenia dan Nephrolepis sangat tinggi beradaptasi sebagi tumbuhan pioner menutupi lantai hutan akibat adanya gangguan habitat. Marga Glichenia dan Nephrolepis biasanya tumbuh bergabung dengan jenis lain walaupun temperatur tanah sangat panas karena adanya intensitas matahari mencapai lantai hutan sangat tinggi. Jenis tersebut dari hasil penelitian ini adalah $G$. linearis, $N$. hirsutula dan N.falcata. Selain itu dilaporkan juga bahwa, jenis $N$. hirsutula, $G$. linearis, $S$. palustris dan $B$. orientale selalu tumbuh pada habitat yang terbuka dan hidupnya tidak pernah ada pada tempat terlindung yang sangat gelap.

Selain spora berukuran sangat kecil, dan adaptasi terhadap lingkungan yang ekstrem cukup tinggi, ada kelebihan sifat yang dimiliki oleh jenis paku tanah yang terdata yaitu dari genus Pteridium dan Gleichenia. Kedua genus tersebut mempunyai akar rimpang dalam tanah sangat dalam. Hal ini dimungkinkan agak tahan terhadap panas dari kebakaran yang melanda sehingga masih dapat hidup, kemudian akan tumbuh kembali mengeluarkan trubus baru di atas permukaan tanah dengan dukungan intensitas cahaya yang cukup.

\section{Dominansi dan Nilai Penting}

Keadaan kawasan hutan gambut pasca kebakaran dari lima dominasi tertinggi dicapai tiga jenis paku-pakuan, satu herba menjalar dan satu jenis semak. Jenis-jenis tersebut adalah $S$. palustris (Burm.) Bedd $(\mathrm{DR}=65.75 \%), B$. orientale $(\mathrm{DR}=6.35 \%)$, Erycibe $s p(\mathrm{DR}=5.79 \%)$, Ficus cf deltoidea. $(\mathrm{DR}=4.68 \%)$ dan Pteridium aquilinum $(\mathrm{DR}=4.23 \%)$. Adapun lima jenis terendah tergolong semai pohon dengan dominansi relatifnya masing-masing $0.11 \%$. Jenis-jenis tersebut adalah Dyera lowi, Garcinia sp, Cratoxylum arborescens, Combretocarpus rotundatus, dan Ctenolophon parvifolius. Untuk jenis $S$. palustris selain tingginya nilai dominansi relatif diikuti juga oleh tingginya niai frekuensi relatif dan menunjukan nilai yang signifikan dibandingkan jenis lainnya. Jenis ini terdapat pada 86 anak petak atau sebesar $43 \%$ dari total petak yang didata, begitu juga untuk jenis $B$. orientale terdapat pada 17 anak petak $(8.5 \%)$ dari total petak yang di data.

Nilai penting tertinggi tetap masih dicapai oleh jenis S. palustris sebesar $119.50 \%$ (Tabel 1). Data tersebut menunjukan hasil nilai sangat jauh berbeda dari tiap-tiap jenis yang terdata, keadaan ini dapat menggambarkan pola dominansi suatu jenis utama dalam suatu kawasan, yaitu menujukan suatu vegetasi hutan hanya dikuasai oleh satu jenis atau terjadi pemusatan pada satu jenis tumbuhan (Odum, 1971). Dengan perbedaan yang signifikan tersebut menujukan bahwa jenis $S$. palustris dapat tumbuh cepat merajai untuk menutupi lantai hutan pasca kebakaran di Kalampangan ini, walaupun keadaan habitatnya miskin zat hara dan ekstremnya $\mathrm{pH}$ tanah. Adapun pada $\mathrm{pH}$ tanah yang asam sangat sedikit jenis tumbuhan yang dapat tumbuh subur dan hanya sedikit pula 
jenis tumbuhan yang dapat beradaptasi dengan sempurna.

Jika dilihat dari daya survival suatu jenis tumbuhan seperti dikemukakan oleh Kissinger (2002) bahwa dominansi dari suatu jenis pada tiap tingkat dapat memberikan petunjuk adanya kekuatan yang lebih dari suatu jenis dalam komunitas hutan. S. palustris memiliki daya survival yang tinggi dibandingkan dengan jenis lainnya. Jenis Dyera lowi, Garcinia sp, Cratoxylum arborescens, Combretocarpus rotundatus, dan Ctenolophon parvifolius memiliki daya survival yang rendah, tetapi jenis tersebut merupakan penyusun tegakan komposisi penerus selanjutnya, baik untuk hutan sekunder maupun hutan primer.

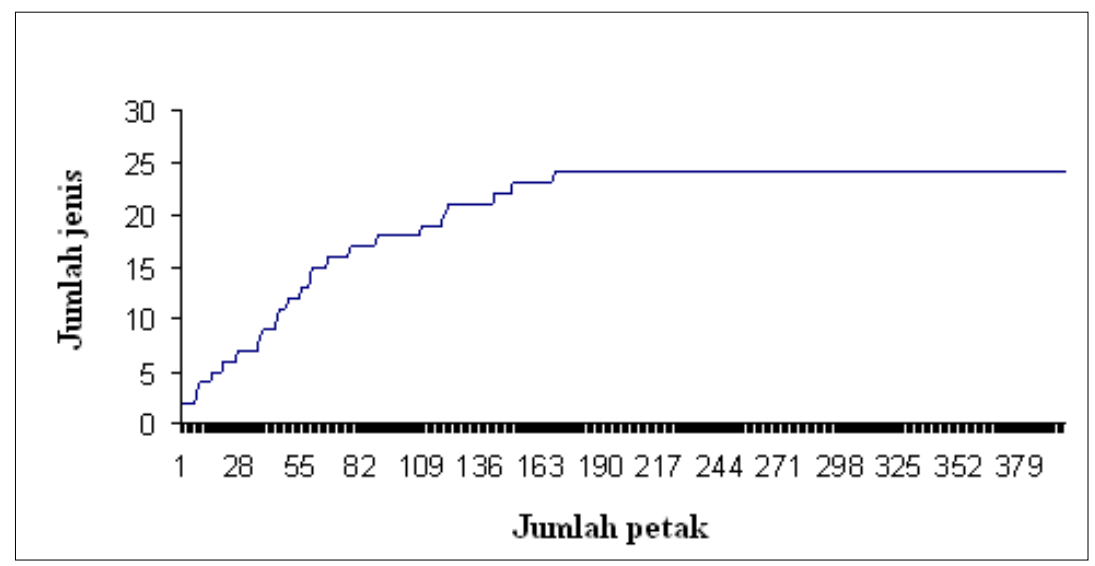

Gambar 2. Kurva penambahan jenis pada hutan gambut pasca kebakaran di Kalampangan-Kalimantan Tengah.

Tabel 1. Komposisi jenis, suku hasil analisis dominansi relatif (DR), frekuensi relatif (FR) dan nilai penting (NP) pada hutan pasca kebakaran di Kalampangan.

\begin{tabular}{cllrrr}
\hline \hline No. & \multicolumn{1}{c}{ Jenis } & \multicolumn{1}{c}{ Famili } & DR (\%) & FR (\%) & NP(\%) \\
\hline \hline 1 & Stenochlaena palustris (Burm.) Bedd. & Pteris group & 65.75 & 53.75 & 119.50 \\
2 & Blechnum indicum Burm.f. & Blechnaceae & 6.35 & 10.63 & 16.98 \\
3 & Erycibe sp & Convolvulaceae & 5.79 & 5.00 & 10.79 \\
4 & Ficus sp & Moraceae & 4.68 & 4.38 & 9.06 \\
5 & Pteridium aquilinum (L.) Kuhn. & Denstaedtiaceae & 4.23 & 2.50 & 6.73 \\
6 & Gleichenia linearis (Burm.) C.B.Clarke & Gleicheniaceae & 2.67 & 1.88 & 4.55 \\
7 & Adenanthera paponina Linn. & Fabaceae & 2.34 & 1.88 & 4.22 \\
8 & Nephrolepis hirsutula (G. Forst.) C.Presl. & Davaliaceae & 1.56 & 2.50 & 4.06 \\
9 & Morinda rigida Miq. & Rubiaceae & 2.01 & 1.88 & 3.88 \\
10 & Melastoma malabatricum Blanco. & Melastomataceae & 0.71 & 2.50 & 3.21 \\
11 & Nephrolepis falcata (Cav.) C.chr. & Oleandraceae & 1.00 & 1.88 & 2.88 \\
12 & Syzygium sp. & Myrtaceae & 0.45 & 1.88 & 2.32 \\
13 & Imperata cylindrica Beauv. & Poaceae & 0.33 & 1.88 & 2.21 \\
14 & Knema sp. & Myristicaceae & 0.22 & 1.25 & 1.47 \\
15 & Macaranga caladifolia Becc. & Euphorbiaceae & 0.22 & 1.25 & 1.47 \\
16 & Psychotria sp. & Rubiaceae & 0.45 & 0.63 & 1.07 \\
17 & Nepenthes sp. & Nepenthaceae & 0.33 & 0.63 & 0.96 \\
18 & Ploiarium altenifolium Melchior & Theaceae & 0.33 & 0.63 & 0.96 \\
19 & Dyera lowi Hook.f. & Apocynaceae & 0.11 & 0.63 & 0.74 \\
20 & Garcinia sp. & Clusiaceae & 0.11 & 0.63 & 0.74 \\
21 & Cratoxylum arborescens Blume & Clusiaceaceae & 0.11 & 0.63 & 0.74 \\
22 & Combretocarpus rotundatus Danser. & Rhizophoraceae & 0.11 & 0.63 & 0.74 \\
23 & Ctenolophon parvifolius Oliver. & Olacaceae & 0.11 & 0.63 & 0.74 \\
\hline \hline
\end{tabular}




\section{Simpulan dan Saran}

\section{Simpulan}

Komposisi jenis-jenis tumbuhan sebagai penutup lantai hutan dalam pemulihan kawasan akibat adanya kebakaran di eks lahan gambut sejuta hektar Kalampangan-Kalimantan Tengah sebanyak 23 jenis dari 20 suku. Jenis tersebut di antaranya 6 jenis tergolong paku-pakuan dan 1 jenis rumput. Jenis $S$. palustris mempunyai daya tumbuh dan sebaran sangat tinggi untuk menutupi lantai hutan akibat kebakaran dalam pemulihan kawasan dibandingkan dengan jenis tumbuhan penutup lantai hutan lainnya.

\section{Saran}

Kawasan hutan gambut Kalampangan pasca kebakaran ini merupakan salah satu labolatorium alam yang perlu dipelajari setiap periode perkembangan suksesinya, untuk itu penelitian lanjutan perlu lakukan di kawasan hutan tersebut sampai menjadi hutan gambut yang klimak.

\section{Ucapan Terima Kasih}

Penulis mengucapkan terima kasih kepada Prof. Dr. Herwin Simbolon atas tugas yang diberikan untuk penelitian pengukuran ulang plot permanen pasca kebakaran dan hutan alami hutan Gambut Kalampangan. Terima kasih juga kepada pak Jhon yang telah membantu selama penelitian di lapangan

\section{Daftar Pustaka}

Greig-Smith, P. 1964. Quantitative Plant Ekology. Second Ed. Butterworths. London.

Holttum, R.E. 1965. Ferns Of Malaya. A Revised Flora of Malaya. (An Illustrated Systematic Account of The Malayan Flora, Including Commonly Cultivated Plants). Volume II. Gaverment Printing Office. Singapore. 653 pp.
Kissinger. 2002. Keanekaragaman jenis Tumbuhan, Stuktur Tegakan dan Pola Sebaran Beberapa specie pohon Tertentu di hutan Kerangas. Thesis Program Pasca Sarjana. Institut Pertanian Bogor. (tidak dipublikasi).

Mackinon, K.G.H., Halim, H. dan Mangalik, A. 1994. Ekologi Kalimantan. Seri Ekologi Indonesia Buku III. Prenhallindo. Jakarta. $806 \mathrm{Hlm}$.

Odum, P.W. 1971. Fundamental of Ecologycal $3^{\text {rd }}$ ED.W.B. Sounder. Coy. Philadelphi. London Toront. hlm $1-24$.

Rahajoe, J.S., Simbolon, H., Sadili, A. dan Nurdin. 2004. Hasil Pendahuluan Penelitian Produksi Serasah di Hutan Gambut Disekitar Daerah Pasca Kebakaran, Serta Kandungan Hara Tanah Gambut di Hutan Alami dan Hutan Bekas Terbakar. Laporan Teknik. Puslit Biologi-LIPI. Bogor.

Sastrapradja, T., Afriastini, J.J., Darnaedi, D. dan Elisabeth, A.W. 1979. Jenis Paku Indonesia. Lembaga Biologi Nasional-Lembaga Ilmu Pengetahuan Indonesia. Bogor.

Simbolon, H. 2004. Proses Awal Pemulihan Hutan Gambut Kelampangan Kalimantan Tengah Pasca Kebakaran Hutan Desember 1997 dan September 2002. Berita Biologi, 7 (3): 145-154.

Usup, A., Takahashi, H. dan Suwido, H.L. 2000. Aspect and Mechanism of Peat Tire in Tropical Peat Land: A Case Study in Central Kalimantan 1997. In: Iwakuma, T., Inoue, T., Osaki, M., Simbolon, H., Tachibana, H., Takahashi, H., Tanaka, N. and Yabe, K. (Eds.). Proceeding of The International Symposium on: Tropical Peat Lands. Bogor-Indonesia 22-23 Nop. 1999. Graduate School of Environmental Earth Sciense Hokkaido University, Sapporo and Research and Development Center for Biology. The Indonesian Institute of Science. BogorIndonesia. 